\title{
Evaluation of Prognostic Factors Affecting Disease-Free Survival and Overall Survival in Patients with Operated Gastric Cancer Treated with Adjuvant Treatment
}

\section{Opere Mide Kanserli Adjuvan Tedavi Alan Hastalarda Hastalıksız Sağkalım ve Genel Sağkalıma Etki Eden Prognostik Faktörlerin Değerlendirilmesi}

\author{
İrem Bilgetekin ${ }^{1}$, Cengiz Karaçin ${ }^{1}$, Fatma Buğdaycı Başal ${ }^{1}$, Umut Demirci ${ }^{2}$, Ömür Berna Oksuzoglu ${ }^{1}$ \\ ${ }^{1}$ Sağlık Bilimleri Üniversitesi, Dr Abdurrahman Yurtaslan Ankara Onkoloji Eğitim ve Araştırma Hastanesi,Tıbbi \\ Onkoloji Kliniği, Ankara \\ ${ }^{2}$ Üsküdar Üniversitesi, Memorial Ankara Hastanesi, Tıbbi Onkoloji Kliniği, Ankara, Türkiye
}

\section{ÖZET}

GİRIŞ ve AMAÇ: Çalışmamızda, mide kanserli hastalarda operasyon sonrası hastalıksız sağkalım ve genel sağkalımı etkileyen prognostik faktörlerin retrospektif olarak değerlendirilmesi amaçlandı

YÖNTEM ve GEREÇLER: Çalışmamızda, Ocak 2014 - Aralık 2018 tarihleri arasında merkezimizde mide kanseri tanısıyla adjuvan tedavi alan 194 hastanın araştırma kapsamında tıbbi kayıtları sistem notlarından ve hasta dosyalarından retrospektif olarak incelendi. Mide kanseri nedeniyle opere olup adjuvan tedavi alan, 18 yaş ve üzerindeki hastalar çalışma grubuna dahil edildi. Sekonder malignite, peritoneal tutulum veya uzak metastaza sahip olan hastalar çalışmaya dahil edilmedi. Sağkalım sürelerinin gruplar arası karşılaştırılmasında Log-Rank testi, sağkalım için prognostik faktörlerinin belirlenmesinde Cox Regresyon modeli kullanıldı.

BULGULAR: Çalışma grubunu oluşturan 194 hastanın \%66.0'sı erkek, \%34.0'ü kadın olup; medyan yaş 60 (2685) idi. Tek değişkenli analizde, ECOG performans skorunun artışı, ileri Tümör (T), Nod (N), ileri Tümör, Nod, Metastaz (TNM) evresi, artmış metastatik lenf nodu oranı hastalıksız ve genel sağkalım için kötü prognostik faktörler olarak bulundu. Lenfovasküler invazyonun olması ise; yalnızca hastalıksız sağkalım için kötü prognostik faktör olarak saptandı. Cox regresyon analizinde, genel sağkalım için ileri T evresi ve ileri TNM evresi, hastalıksız sağkalım için ise, ileri T evresi bağımsız kötü prognostik faktörler olarak tespit edildi.

TARTIŞMA ve SONUÇ: Elde edilen sonuçlara göre, opere mide kanserli hastalarda, ileri T evresi ve TNM evresinin genel sağkalım açısından kötü prognostik faktörler olabileceği, ayrıca ileri $\mathrm{T}$ evresinin hastalıksız sağkalımı olumsuz etkilediği gösterildi.

Anahtar Kelimeler: Mide kanseri, Gastrektomi, Prognostik Faktörler, Sağkalım

\section{ABSTRACT}

INTRODUCTION: The aim of the study was to retrospectively evaluate the prognostic factors affecting the disease-free survival and overall survival in gastric cancer patients after the operation.

METHODS: In the study, the medical records of 194 patients who received adjuvant therapy with the diagnosis of gastric cancer in our center between January 2014 and December 2018 were retrospectively analyzed from the system notes and patient files. Gastric cancer patients aged 18 years or older who underwent operation were included in the study group. Secondary malignancy, peritoneal involvement or distant metastasis were not included in the study group. Log-Rank test was used to compare survival times between groups, and Cox Regression analysis was used to determine prognostic factors for survival.

RESULTS: The median age of 194 patients (66.0\% male, $34.0 \%$ female) was 60 (26-85). In univariate analysis; poor performance score, advanced Tumor (T) stage, advanced Node (N) stage, advanced Tumor, Node, Metastasis (TNM) stage, and increased metastatic lymph node ratio were found to be poor prognostic factors for disease-free survival and overall survival. Lymphovascular invasion was found only as a poor prognostic factor for diseasefree survival. In Cox regression analysis, advanced T stage and advanced TNM stage for overall survival and advanced $\mathrm{T}$ stage for disease-free survival were determined as independent poor prognostic factors.

DISCUSSION AND CONCLUSION: According to the results obtained, it was shown that advanced T stage and TNM stage may be poor prognostic factors in terms of overall survival in patients with operated gastric cancer and also advanced $\mathrm{T}$ stage negatively affected disease-free survival. 
Keywords: Gastric Cancer, Gastrectomy, Prognostic Factors, Survival

\section{GíRiş}

Mide kanserleri, dünya çapında en sık görülen dördüncü kanser olup; kötü prognostik özellikleri ile önemli bir sağlık sorunu olmaya devam etmektedir. Her y1l 950.000'den fazla yeni mide kanseri tanısı konulmaktadır (1). GLOBOCAN 2018 verilerine göre, mide kanseri, akciğer ve kolorektal kanseri takiben, dünya çapında kanser ölümlerinin üçüncü önde gelen nedenidir (2).

Mide kanserlerinin en s1k görülen tipi adenokarsinomlardır (\%95) (3). Mide adenokarsinomları anatomik bölgelerine göre kardiyak ve kardiyak olmayan olarak sınıflandırılmaktadır. Gastrik kardiya kanserleri, gastroözefageal bileşkeye bitişik bölgede ortaya çıkmaktadır ve özefagus adenokarsinomu ile benzer epidemiyolojik özellikler taşımaktadır. Distal mide kanseri olarak da bilinen kardiyak olmayan kanserler daha sık görülmektedir ve midenin alt kısmında ortaya çıkmaktadır(3).

Operabl mide kanserli hastalarda küratif cerrahi ve lenf nodudiseksiyonu mide kanseri için en önemli tedavi stratejisi olarak kabul edilmektedir (4).Küratif cerrahiye rağmen; hastaların \%21.8-63.4'ünde rekürrens, peritoneal yayılım veya uzak metastaz görüldügü ve bunun da kötü prognoza neden olduğu bildirilmektedir (5). Bu sonuçlar sadece cerrahinin tedavide yeterli olmadığını göstermektedir. $\mathrm{Bu}$ da cerrahiye ek olarak adjuvan tedaviyi bu hastalar için bir öncelik haline getirmektedir (6). Cerrahi rezeksiyon uygulanan mide kanseri vakalarında nüksü önlemek ve sağkalımı artırmak için adjuvankemoterapi (KT) veya adjuvankemoradyoterapi (KRT) tercih edilebilmektedir (7).

Mide kanseri teşhisi alan hastaların çoğu hastalığın ileri evresinde başvurmaktadır bu nedenle sağkalım oranı düşüktür (8). Yaş, cinsiyet, beslenme durumu, komorbiditeler, lokalizasyon, boyut, invazyon derinliği, tümörün histolojik özellikleri, lenfovasküler invazyon, nodal durum, küratif cerrahi , cerrahi sınır, lenf nodu disseksiyonu tipi, adjuvan tedavi önemli prognostik faktörlerden bazılarıdır(9). Mide kanseri hastalarında, klinik ve patolojik prognostik faktörlerin tanımlanması önemlidir. Çünkü prognostik faktörler seçilecek tedaviler hakkında yol gösterici olabilmekte ve sağkalımın arttırılmasını sağlayabilmektedir (8).

Çalışmamızın amacı, merkezimizde opereolmuş mide kanserli hastalarda hastalıksız sağkalım ve genel sağkalımı etkileyen prognostik faktörlerin retrospektif olarak değerlendirilmesidir.

\section{MATERYAL METOD}

Araştırma kapsamında, Ocak 2014 - Aralık 2018 tarihleri arasında merkezimiz medikal onkoloji kliniğinde mide kanseri nedeniyle adjuvan tedavi alan 194 hastaya ait tıbbi kayıtlar, hasta dosyalarından ve elektronik kayıt sisteminden retrospektif olarak incelendi. Çalışmaya mide kanseri tanısı ile opere olmuş 18 yaş ve üzerindeki hastalar dahil edildi. Herhangi bir ikincil malignitesi olan, peritonealtutulumlu veya uzak metastazlı hastalar çalışma grubuna dahil edilmedi.

\section{Çalışmamız Tıpta Uzmanlık ve Eğitim} Kurulu (toplant1 numaras1: 75, tarih: 30.07.2019) tarafından onaylanmıştır.

Hastaların yaşı cinsiyeti, performans durumu- ECOG-PS (Eastern Cooperative Oncology Group - Performance Status), tümörün yerleşim yeri,tümör histopatolojisi, TNM evresi,postoperatif cerrahi sınır,çıkarılan toplam ve metastatik lenf nodu sayısı, adjuvan radyoterapi varlığı dosyalarından kaydedildi. 
Prognostik faktörlerin genel sağkalım ve hastalıksız sağkalıma etkisi değerlendirildi. Genel sağkalım hastalığın tanı tarihinden ölüme kadar geçen süre olarak tanımlandı. Hastalıksız sağkalım ise; adjuvan tedavi sonrası hastalık progresyonu ya da herhangi bir nedenle ölüme kadar geçen süre olarak tanımlandı.

Çalışmada kullanılan TNM (Tümör, Nod, Metastaz) evrelemesi Dünya Sağlık Örgütü tarafından yayınlanan sinıflandırmaya göre yapıldı. Metastatik lenf nodu oranı, metastatik lenf nodu sayısının toplam lenf nodu sayısına bölünmesiyle hesaplandı.

\section{İstatistiksel Analizler}

Araştırma sonucu elde edilen verilerin analizi SPSS v21 (SPSS Inc., Chicago, IL, USA) istatistik programı ile yapıldı. Tanımlayıcı verilerin değerlendirilmesinde sayı (n), yüzde, ortanca, minimum ve maksimum değerleri kullanıldı. Sağkalım sürelerinin gruplar arası karşılaştırılmasında Log-Rank testinden faydalanıldı. Sağkalım süreleri için prognostik faktörlerinin belirlenmesinde ileriye dönük seçimli Cox Regresyon Analizi kullanıldı. İstatistiksel olarak anlamlılık sinırı $\mathrm{p}<0.05$ olarak kabul edildi.

\section{SONUÇLAR}

Çalışma grubunu oluşturan 194 hastanın 128 'i (\%66.0) erkek, 66's1 (\%34.0) kadın veortanca yaş 60 (26-85) idi.<60 yaş hasta oran $1 \% 54$ iken; $\geq 60$ yaş hasta oranı $\% 46$ idi. Çalışma grubunu oluşturan hastaların \%47.4'ünün ECOG-PS'si 0, \%22.2'sinin kitlesi gastroözefageal bileşkede, \%70.1'inin ameliyat tipi total gastrektomi, \%70.1'inin histopatolojik tipi adenokarsinom, \%44.3'ü T3 evrede, \%52.6's1 N3 evrede, \%74.8'i Evre III, \%99.0'unun cerrahi sinır1 negatif, \%70.6's1 adjuvanradyoterapi (RT) tedavisi almıştı. Hastalardan çıarılan lenf nodu sayısı ortancası 26 (3-78), metastatik lenf nodu sayıs1 ortancas1 7 (0-38) bulundu (Tablo 1).

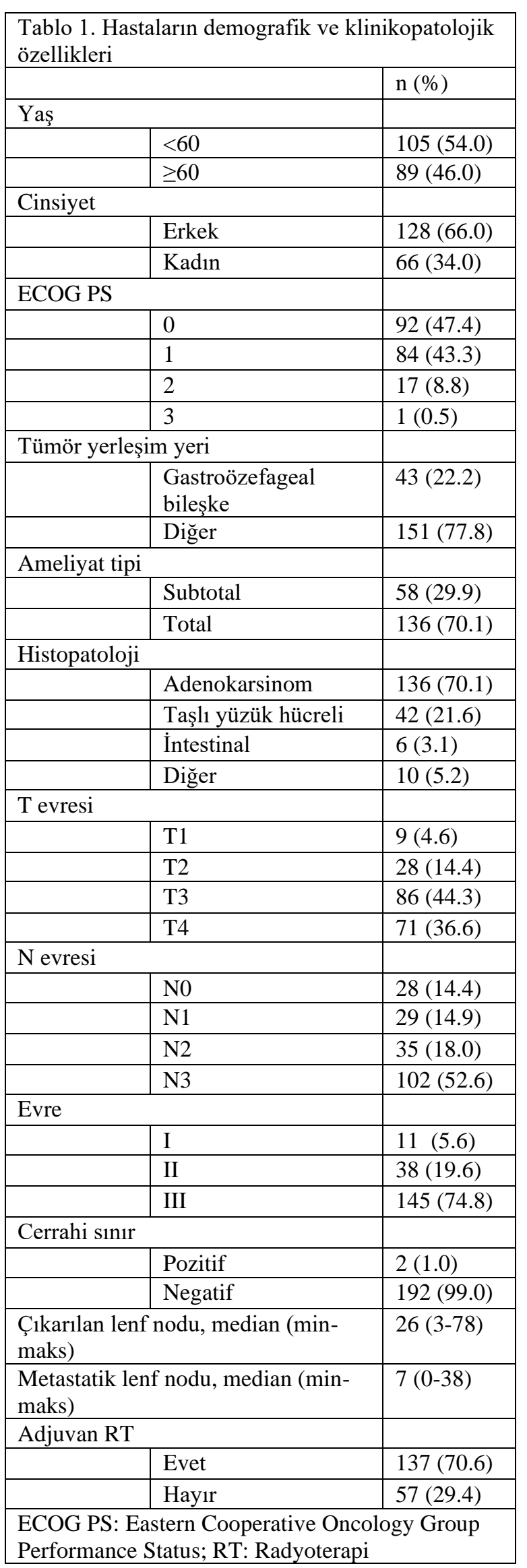


Çalışma grubundaki hastalara uygulanan kemoterapötiklerarasında en sik kullanılan rejimler FOLFOX (\%33.5), CAPEOX (\%27.8), FUFA (\%17.5), Sisplatinkapesitabin (\%14.5),Kapesitabin (\%6.7) idi (Tablo 2).

\begin{tabular}{|l|l|}
\hline \begin{tabular}{l} 
Tablo 2. Hastalara uygulanan kemoterapi \\
rejimleri ve kullanım oranları \\
\hline
\end{tabular} & n (\%) \\
\hline $\begin{array}{l}\text { FOLFOX (5-Fluorourasil, } \\
\text { Lökoverin, Oksaliplatin) }\end{array}$ & $65(33.5)$ \\
\hline $\begin{array}{l}\text { CAPEOX (Kapesitabin, } \\
\text { Oksaliplatin) }\end{array}$ & $54(27.8)$ \\
\hline FUFA (5-Fluorourasil, Folinik Asit) & $34(17.5)$ \\
\hline Sisplatin-kapesitabin & $28(14.5)$ \\
\hline Kapesitabin & $13(6.7)$ \\
\hline Toplam & 194 \\
& $(100.0)$ \\
\hline
\end{tabular}

Çalışma grubunda ECOG-PS skoru 0 olmayanlarda, metastatik lenf nodu oran $1 \geq 0.25$ olanlarda,tümör boyutu $\geq \mathrm{T} 3$ olanlarda, N 2-3 evrede olanlarda ve Evre III hastalıkta hastalıksız sağkalımve genel sağkalım süresi anlamlı olarak daha kisayd. Lenfovaskülerinvazyon pozitif olanlarda hastalıksız sağkalım süresi anlamlı derecede daha kısa idi (Tablo 3.)

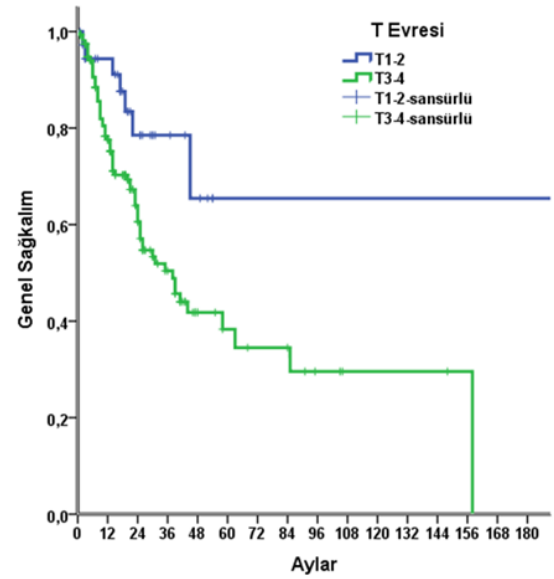

Şekil 1. T evresine göre genel sağkalım değişimi
Yapilan Cox regresyon analizi neticesinde ileri T (Tümör) evresi ve ileri TNM evresi genel sağkalım açısından bağımsız prognostik faktörler olarak tesbit edildi.Yalnızca ileri $\mathrm{T}$ evresi ise hastalıssı sağkalım açısından kötü prognostik faktör olarak tespit edildi. $\geq \mathrm{T} 3$ evrede olanlar olmayanlarla kıyaslandığındamortalite riskinin $\geq \mathrm{T} 3$ evrede olanlarda 2.63 (1.04-6.62) kat yüksek olduğu saptandı (Şekil 1, Tablo 4). Evre III olan mide kanseri hastalarında mortalite riskinin Evre I-II olanlara göre 2.65 (1.24-5.67) kat yüksek olduğu bulundu (Şekil 2, Tablo 4). Hastalıksız sağkalım açısından bakıldığında. T3-4 evre mide kanseri hastalarında nüks/progresyon gelişme riskinin T1-2 olanlara göre 2.50 (1.14-5.48) kat yüksek olduğu saptand1 (Şekil 3, Tablo 4). Çok değişkenli analize dahil edilen cinsiyet, ECOG-PS, N evresi, metastatik lenf nodu oranı, lenfovasküler invazyon ve perinöralinvazyon ile hastalısız ve genel sağkalım sürelerinde arasında bir ilişki bulunamadı (Tablo 4.)

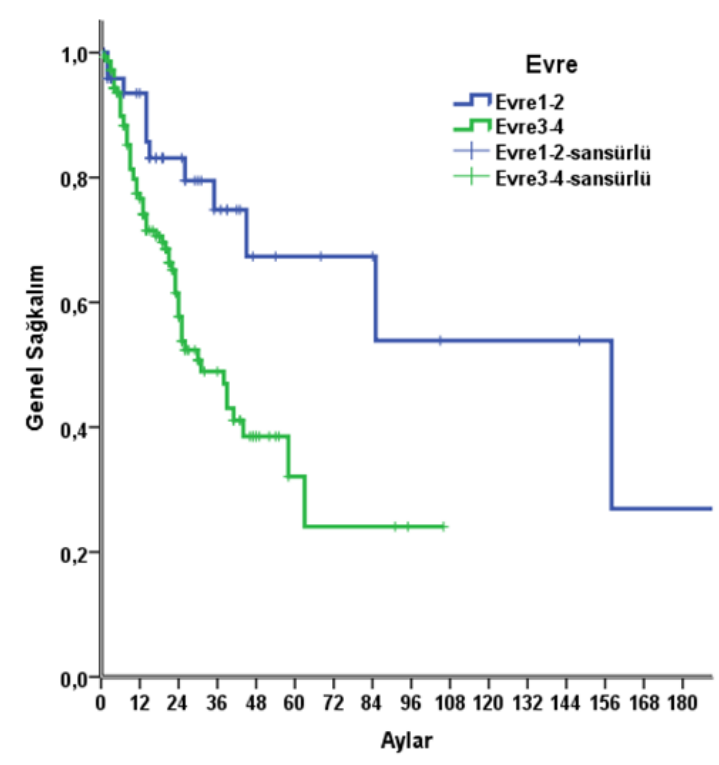

Şekil 2. TNM evresine göre genel sağkalımın değişimi

\section{TARTIŞMA}


Mide kanseri, artmış metastaz riski ve yüksek mortalite oranına ek olarak,erken tanının veradikal rezeksiyon şansının düşük olduğu bir kanser türüdür(10). Mide kanseri için prognostik faktörlerin belirlenmesi tedavi sürecine yön verilebilmesi açısından önemlidir veprognostik faktörler farklı hasta grupları için değişkenlik göstermektedir $(8,11)$. Bu araştırmada opere olmuş mide kanseri hastalarında, sağkalım sürelerine etki eden prognostik faktörleri retrospektif olarak inceledik.

Araştırmada yaş gruplarına göre hastalıksız ve genel sağkalım sürelerinin farklılık göstermediği bulundu. Daha önce yapılan araştırmalarda da mide kanseri hastalarında, sağkalımın yaş ile değişim göstermediği bildirilmiştir (12, 13). Ancak, artan yaşın sağkalım süresini kısaltan bir faktör olduğunu bildiren çalışmalar da vardır (14). Çalışmalarda yaş grupları için farklı sınır değerlerin seçilmesi, grupların yaş dağılımının benzer olmaması, ileri yaşta ölüme neden olan başka hastalıklarında söz konusu olması çalışmalar arasındafarklı sonuçların elde edilmesine yol açmış olabilir.

Çalışmamızda, mide kanseri hastalarında, genel ve hastalıksız sağkalım sonuçlarının kadın ve erkekler arasında benzer olduğu bulundu. Araştırmada elde edilen sonuç, mide kanseri hastalarında, cinsiyetin sağkalım üzerine etkili faktörlerden biri olmadığını gösteren çalışmaların sonuçlarıyla benzerdi (13).(15). Diğer yandan, Tokunaga ve arkadaşlarının araştırmasında, çok değişkenli analizde erkek cinsiyete sahip olmanın sağkalım süresini kısaltan bağımsız bir risk faktörü olarak bulunduğu bildirilmiştir (14).

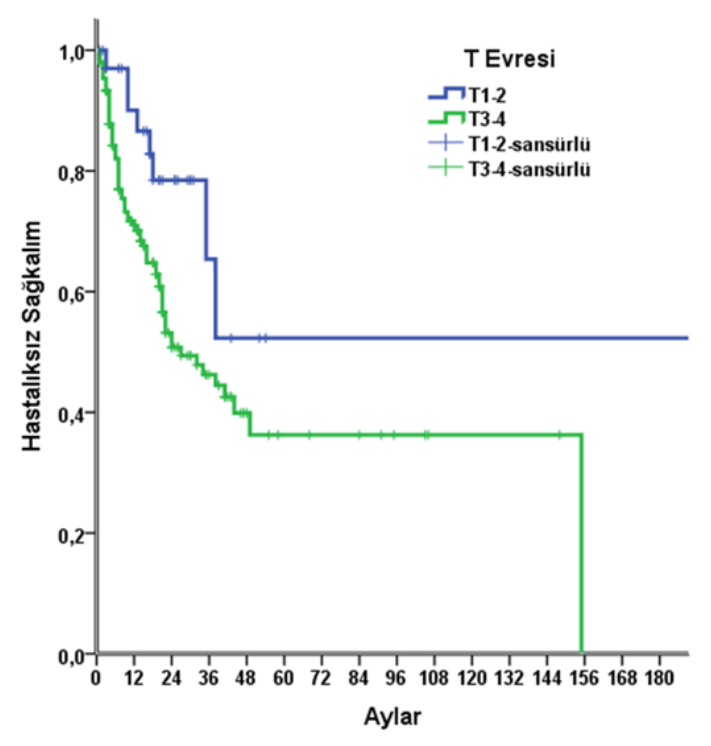

Şekil 3. T evresine göre hastalıksız sağkalım süresinin değişimi 
ECOG-PS, hastaların fiziksel tek değişkenli analizde sağkalım üzerine etkili durumunu değerlendirmek için kullanılan bir prognostik faktörlerden biri olarak bulunduğu

\begin{tabular}{|c|c|c|c|c|}
\hline & Hastaliksız Sağkalim & & Genel Sağkalm & \\
\hline & Ortanca (\%95 GA) & $\mathrm{p}$ & Ortanca (\%95 GA) & $\mathrm{p}$ \\
\hline \multicolumn{5}{|l|}{ Yaş grubu } \\
\hline$<60$ & $38(29.946 .1)$ & 0.461 & $45(31.2-53.5)$ & 0.151 \\
\hline$\geq 60$ & $32(11.5-52.5)$ & & $35(24.2-57.7)$ & \\
\hline \multicolumn{5}{|l|}{ Cinsiyet } \\
\hline Erkek & $32(18.445 .6)$ & 0.112 & $41(20.5-61.5)$ & 0.063 \\
\hline Kadin & Ulaşılamadı & & Ulaşılamadı & \\
\hline \multicolumn{5}{|l|}{ ECOGPS } \\
\hline 0 & Ulaş̧lamadı & 0.003 & Ulaşılamadı & 0.004 \\
\hline $1-2-3$ & $22(15.9-28.1)$ & & $26(24.2-57.7)$ & \\
\hline \multicolumn{5}{|l|}{ Tümör yerleşim yeri } \\
\hline Gastroözefageal junction & $49(13.0-84.9)$ & 0.546 & $58(13.8-102.2)$ & 0.761 \\
\hline Diğer & $35(22.347 .7)$ & & $39(26.1-51.9)$ & \\
\hline \multicolumn{5}{|l|}{ Ameliyat tipi } \\
\hline Subtotal & $35(15.5-54.5)$ & 0.444 & $38(24.1-51.9)$ & 0.960 \\
\hline Total & $41(25.1-56.9)$ & & $44(17.0-70.9)$ & \\
\hline \multicolumn{5}{|l|}{ Histolopatoloji } \\
\hline Taşh yüzükhücreli & $21(1.0-41.0)$ & 0.263 & $30(17.2-42.8)$ & 0.209 \\
\hline Adenokarsinomve diger & $41(27.1-54.9)$ & & $45(25.8-64.1)$ & \\
\hline \multicolumn{5}{|l|}{ T evresi } \\
\hline$T 1-2$ & Ulaşılamadı & 0.028 & Ulaşlamadı & 0.016 \\
\hline T3-4 & $32(18.2-45.7)$ & & $38(25.7-50.2)$ & \\
\hline \multicolumn{5}{|l|}{ Nevresi } \\
\hline $\mathrm{NO}-1$ & $75(14.6-145.4)$ & 0.009 & $85(13.7-156.2)$ & 0.013 \\
\hline $\mathrm{N} 2-3$ & $24(13.8-34.1)$ & & $31(20.941 .0)$ & \\
\hline \multicolumn{5}{|l|}{ TNMEvresi } \\
\hline I-II & $75(12.3-198.5)$ & 0.003 & $158(46.3-219.6)$ & 0.004 \\
\hline III & $24(13.4-34.6)$ & & $31(20.341 .6)$ & \\
\hline \multicolumn{5}{|l|}{ Metas tatik Lenf Nodu Oran1 } \\
\hline$<0.25$ & $75(5.4-124.6)$ & 0.017 & $85(23.5-146.5)$ & 0.039 \\
\hline$\geq 0.25$ & $24(14.9-33.0)$ & & $31(19.7-42.2)$ & \\
\hline \multicolumn{5}{|l|}{ Lenfovaskilerinvazyon } \\
\hline Var & $22(10.8-33.2)$ & 0.008 & $39(21.8-56.1)$ & 0.083 \\
\hline Yok & $44(12.4-74.3)$ & & $63(22.9-103.0)$ & \\
\hline \multicolumn{5}{|l|}{ Perinöralinvazyon } \\
\hline Var & $22(7.4-36.6)$ & 0.142 & $25(9.6-40.3)$ & 0.116 \\
\hline Yok & $38(28.4-47.6)$ & & $44(36.6-51.3)$ & \\
\hline \multicolumn{5}{|l|}{ Adjuvan RT } \\
\hline Evet & $35(17.2-52.8)$ & 0.260 & $41(22.2-59.8)$ & 0.367 \\
\hline Hayır & $38(24.9-51.0)$ & & $58(33.9-82.0)$ & \\
\hline
\end{tabular}

skorlama olup; ayn zamanda tedavi ile sağkalım oranlarını predikte edebilen, yaygın kullanılan bir prognostik faktördür (16). Çalışmamızda ECOG-PS skor artışının tek değişkenli analizde hastalıksız ve genel sağkalım süresini azalttığ 1 saptand1. Buonadonna ve arkadaşlarının araştırmasında da benzer şekilde performans skorunun sadece rapor edilmiştir (17). Yücel ve arkadaşlarının araștırmasında hem tek değișkenli analizde hem de çok değişkenli analizde ECOGPS'ninsağkalım üzerine etkili prognostik faktörlerden biri olarak bulunduğu bildirilmiştir (18). Mide kanseri evresi ilerledikçe hastaların genel durumu daha da kötüleşir ve performans skor derecesi tedavi tolerasyonunu zorlaştıracak 
şekilde $\operatorname{artar}(19)$. Çalışmamızda çok değişkenli analizde evrenin genel sağkalım üzerine etkisi gösterilmiştir.

Çalışmamızda tümör lokalizasyonu ve histopatolojik tipi ile sağkalım süreleri arasında anlamlı bir ilişki saptanamadı. Başka araştırmalarda da lokalizasyon $(13,15,18)$ ve histopatolojik tiple $(15,18)$ ilgili benzer bulgular rapor edilmiştir. Green ve arkadaşlarının araştırmasında midenin tamaminda bulunan ve diffüz histolojik tipte mide kanserli hastaların sağkalım süresinin daha kısa bulunduğu ve bu faktörlerin çok değişkenli analizde de sağkalımı etkileyen bağımsız risk faktörleri olduğu bildirilmiştir (20).Başka bir araştırmada diffüz-mikst tipte mide kanserinin tek ve çok değişkenli analizde sağkalımıkısaltan prognostik faktör olduğu bildirilmiştir(21).Buonadonnave arkadaşlarının araştırmasında, mide kanseri hastalarında tümör lokalizasyonunun hem tek değişkenli hem çok değişkenli analizde sağkalım üzerine etkili prognostik faktör olarak bulunduğu bildirilmiştir (17).

Total gastrektomi teknik olarak subtotal gastrektomiden daha zordur. Ayrica total gastrektomi ameliyat1, sonrasında daha uzun bir süre hastanede kalmayı gerektirmektedir (22). Çalışmamızda operasyon tipinin sağkalımı etkileyen prognostik faktörler arasında olmadığı saptandı. Mita ve arkadaşlarının bildirdiği sonuç da elde ettiğimiz bulguyu desteklemektedir (23). Başka bir araştırmada, çok değişkenli analiz sonucunda total gastrektomiye göre proksimal gastrektomide mortalite riskinin daha az bulunduğu, subtotal, distal, parsiyel gastrektomi açısından anlamlı bir farklılık bulunamadığı bildirilmiştir (24). Wang ve arkadaşlarının araştırmasına göre total gastrektomidesağkalım oranının proksimal ve distal gastrektomiye göre daha düşük bulunduğu bildirilmiştir (21).

Araştırmada metastatik lenf nodu oranı artışının, mide kanseri hastalarında tek değişkenli analizde hastalıksız ve genel sağkalımı azalttığı, çok değişkenli analizde ise sağkalım üzerine anlamlı bir etkisinin olmadığ saptand. Araştırmada elde ettiğimiz sonuç, mide kanserleri için daha önce bildirilen tek değişkenli ve çok değişkenli analizlerde metastatik lenf nodu oranının sağkalım üzerine etkili prognostik faktör olarak bulunduğunu bildiren araştırmaların sonuçlarından çok değişkenli analizde bir ilişki saptanamaması nedeniyle farklıdır(21).

Tümörün venöz veya lenfatik dolaşıma invazyonu metastatik hastalığa neden olur. $\mathrm{Bu}$ nedenle lenfovaskülerinvazyon olduğunda sağkalım süresi azalabilmektedir $(25,26)$. Çalışmamızda lenfovasküler invazyonun, postoperatif mide kanseri hastalarında hastalıksız sağkalımı olumsuz etkileyen faktörlerden biri olduğu, çok değişkenli analizde bu etkinin görülmediği saptand1. Perinöral invazyon ise mide kanseri hastalarında sağkalımı etkileyen faktörlerden biri değildi. Wang ve arkadaşlarının araştırmasında, mide kanseri hastalarında gastrektomi sonrası sağkalım için yapılan hem tek değişkenli hem çok değişkenli analizde lenfovasküler invazyonun kötü prognostik faktör olduğu bildirilmiştir (21). Başka bir araştırmada, tek değişkenli analiz sonucunda, mide kanseri hastalarında perinöralinvazyonun genel ve hastalıksız sağkalımla ilişkili bulunduğu bildirilmiştir (5). Yücel ve arkadaşlarının araştırmasında, mide kanserli hastalarda lenfovasküler ve perinöralinvazyon ile sağkalım arasında anlamlı bir ilişki bulunmadığı bildirilmiştir (18). 


\begin{tabular}{|c|c|c|c|c|}
\hline & \multicolumn{2}{|c|}{ Hastaliksız Sağkalım } & \multicolumn{2}{|l|}{ Genel Sağkalım } \\
\hline & HR $(\% 95 \mathrm{GA})$ & $\mathrm{p}$ & HR $(\% 95 \mathrm{GA})$ & $\mathrm{p}$ \\
\hline \multicolumn{5}{|l|}{ Cinsiyet } \\
\hline Erkek(Referans) & 1.00 & 0.153 & 1.00 & 0.069 \\
\hline Kadin & $0.68(0.39-1.16)$ & & $0.60(0.35-1.04)$ & \\
\hline \multicolumn{5}{|l|}{ ECOG PS } \\
\hline 0 (Referans) & 1.00 & 0.109 & 1.00 & 0.134 \\
\hline $1-2-3$ & $1.54(0.91-2.60)$ & & $1.49(0.88-2.52)$ & \\
\hline \multicolumn{5}{|l|}{ Tevresi } \\
\hline T1-2 (Referans) & 1.00 & 0.023 & 1.00 & 0.040 \\
\hline T3-4 & $2.50(1.14-5.48)$ & & $2.63(1.04-6.62)$ & \\
\hline \multicolumn{5}{|l|}{$\mathrm{N}$ evresi } \\
\hline N0-1 (Referans) & 1.00 & 0.929 & 1.00 & 0.442 \\
\hline $\mathrm{N} 2-3$ & $0.95(0.29-3.08)$ & & $1.48(0.54-4.02)$ & \\
\hline \multicolumn{5}{|l|}{ Evre } \\
\hline I-II(Referans) & 1.00 & 0.393 & 1.00 & 0.012 \\
\hline III & $1.54(0.57-4.16)$ & & $2.65(1.24-5.67)$ & \\
\hline \multicolumn{5}{|c|}{ Metastatik lenf nodu oran1 } \\
\hline$<0.25$ (Referans) & 1.00 & 0.052 & 1.00 & 0.724 \\
\hline$\geq 0.25$ & $1.74(0.99-3.06)$ & & $1.15(0.52-2.54)$ & \\
\hline \multicolumn{5}{|c|}{ Lenfovaskülerinvazyon } \\
\hline Yok(Referans) & 1.00 & 0.054 & 1.00 & 0.844 \\
\hline Var & $1.83(0.99-3.38)$ & & $1.09(0.48-2.46)$ & \\
\hline \multicolumn{5}{|l|}{ Perinöralinvazyon } \\
\hline Yok(Referans) & 1.00 & 0.830 & 1.00 & 0.541 \\
\hline Var & $1.07(0.57-2.03)$ & & $1.18(0.69-2.00)$ & \\
\hline
\end{tabular}

Son 30-40 yıl boyunca, küratif cerrahi uygulanan mide kanseri hastalarında nüksün önlenmesi ve sağkalımın arttırılabilmesi amacıyla KT ve RT içeren multimodal tedaviler yoğun bir şekilde araştırılmasına rağmen, güncel yaklaşımlarda adjuvan tedavideki belirsizlikler devam etmektedir (18). Çalışmamızın tek değişkenli analizinde KT'ye ek olarak RT uygulanmasının hastalıksız ve genel sağkalım üzerine anlamlı bir etkisinin olmadığ 1 saptandı. Yücel ve arkadaşlarının çalışmasında mide kanserlerinde adjuvan kemoradyoterapinin genel ve hastalıksız sağkalımda düzelme sağladığı bildirilmiştir (18). Başka bir araştırmada, tek değişkenli analizde KT ve RT’nin prognozla ilişkili olduğu; çok değişkenli analizde ise sadece KT'nin bağımsız prognostik faktör olduğu bildirilmiştir (17). Araştırmalar arasında saptanan bu farkl1lıkların, kullanılan KT rejimlerinin, hastaların evrelerinin ve diğer klinik özelliklerinin farklı olması ile ilgili olabileceği düşünüldü.

Adress for correspondence

e-mail:

Available at www.actaoncologicaturcica.com

Copyright $\odot$ Ankara Onkoloji Hastanesi
Mide kanseri prognozu için tespit edilen en önemli prognostik faktörlerden biri invazyon derinliği, lenf nodlarının tutulumu ve uzak metastazın incelenmesi ile belirlenen TNM evresidir (15, 17). TNM evresi, onkolojide hastalığın yaygınlığını belirleme, tedavi planını belirleme ve prognoz açısından oldukça önemlidir $(15,17)$. Çalışmamızda ileri T, $\mathrm{N}$ ve TNM evresi tek değişkenli analizde hastalıksız ve genel sağkalımı azaltan faktörler olarak bulundu. Çok değişkenli analiz sonucunda ileri T evresinin genel ve hastallksız sağkalım için, ileri TNM evresinin genel sağkalım için bağımsız kötü prognostik faktör olduğu saptandi. TNM evresi için bulduğumuz sonuç, mide kanseri hastalarında, ileri TNM evresinin tek değişkenli analizde $(15,17)$ ve çok değişkenli analizde sağkalım üzerine etkili prognostik faktörlerden biri olduğunu bildiren çalışmalar ile benzerdi $(15,17)$. Daha önce yapılan çeşitli araştırmalar, tek değişkenli ve çok değişkenli analizlerde daha ileri $\mathrm{N}$ evresine sahip olmanın, mide kanseri hastalarında sağkalım için risk faktörü olduğunu 
bildirmiş̧tir(5, 18). Araştırmada elde ettiğimiz sonuca benzer şekilde $\mathrm{T}$ evresinin sağkalım üzerine istatistiksel olarak anlamlı etkisini bildiren araştırmalar vardır $(5,18,21)$. Buna göre, çalışma grubumuzda T evresi ve TNM evresi prognozu belirlemede diğer faktörlerden daha önemlidir. Literatürde incelenen çoğu çalışmada,çok değişkenli analiz ile elde edilenprognostik faktörler farklılık göstermektedir. Bu durum, çalışma gruplarının klinik özelliklerinin, tedavilerinin farklı olması veya araştırmalarda çok değişkenli analiz dahil edilen değişkenlerin her çalışmada farklı olması ile ilgili olabilir.

Araştırmanın en önemli kısıtlılığ retrospektif bir çalışma olmasıdır. Araştırmada az sayıda mide kanseri hastasına ait sonuçların değerlendirilmiş olması diğer bir sınırlılık olsa da, tek merkez deneyimi için kabul edilebilir sayıda hasta çalışmaya dahil edilmiştir.

\section{SONUÇ}

\section{REFERANSLAR}

1. Ferlay J, Steliarova-Foucher E, Lortet-Tieulent J, et al. Cancer incidence and mortality patterns in Europe: estimates for 40 countries in 2012. Eur J Cancer. 2013;49:1374-403.

2. Bray F, Ferlay J, Soerjomataram I, Siegel RL, Torre LA, Jemal A. Global cancer statistics 2018: GLOBOCAN estimates of incidence and mortality worldwide for 36 cancers in 185 countries. CA Cancer J Clin. 2018;68:394424.

3. Mukaisho $K$, Nakayama $T$, Hagiwara $T$, Hattori $T$, Sugihara H. Two distinct etiologies of gastric cardia adenocarcinoma: interactions among $\mathrm{pH}$, Helicobacter pylori, and bile acids. Front Microbiol. 2015;6:412.

4. Hu Y, Huang C, Sun Y, et al. Morbidity and mortality of laparoscopic versus open D2 distal gastrectomy for advanced gastric cancer: a randomized controlled trial. J Clin Oncol. 2016;34:1350-57.

5. Yang $\mathrm{W}, \mathrm{Hu} \mathrm{R}, \mathrm{Li} \mathrm{G}-\mathrm{c}$, et al. Survival outcomes and patterns of failure after D2 dissection and adjuvant chemoradiotherapy for locally advanced gastric cancer: a retrospective study. The British journal of radiology. 2018;91:20170594.

6. Zhou M-l, Kang M, Li G-c, Guo X-m, Zhang Z. Postoperative chemoradiotherapy versus chemotherapy for R0 resected gastric cancer with D2 lymph node
Çalışmamızda, tek değişkenli analiz sonucunda mide kanserli hastalarda ECOG-PS yüksekliği, ileri $\mathrm{T}$ evresi, ileri $\mathrm{N}$ evresi, ileri TNM evresi, metastatik lenf nodu oranı artışı ve lenfovasküler invazyon sağkalımı olumsuz etkileyen faktörler olarak bulundu. Çok değişkenli analizde, ileri T evresi ve TNM evresi sağkalımı bağımsız olarak etkileyen kötü prognostik faktörler olarak saptandi. Bu sonuca göre, mide kanserli hastalarda T evresi artışının mortalite ve progresyon riskini, ileri TNM evresinin mortalite riskini $\operatorname{arttırdığ}$ söylenebilir. Mide kanseri hastalarında sağkalımı etkileyen prognostik faktörlerle ilgili daha kapsamlı araştırmaların yapılmasına ihtiyaç vardır.

Çıkar çatışması: Yazarların hiçbir çıkar çatışması yoktur. dissection: an up-to-date meta-analysis. World J Surg Oncol. 2016;14:209.

7. Smalley SR, Benedetti JK, Haller DG, et al. Updated analysis of SWOG-directed intergroup study 0116: a phase III trial of adjuvant radiochemotherapy versus observation after curative gastric cancer resection. J Clin Oncol. 2012;30:2327.

8. Akyağci SB, Bağcivan E, Özgüç H, Kirdak T, Korun N. Mide kanserinde prognostik faktörler. Uludağ Üniversitesi Tıp Fakültesi Dergisi.31:113-18.

9. Tulay E, Karacin C, Gokhan U, et al. Efficacy of the Combination of Modified Docetaxel, Cisplatin and Fluorouracil in Locally Advanced Gastric Cancer: Evaluation of Real-Life Outcomes. International Journal of Hematology and Oncology.29:001-09.

10. Wu H, Wang W, Tong $\mathrm{S}$, Wu C. Nucleostemin regulates proliferation and migration of gastric cancer and correlates with its malignancy. Int J Clin Exp Med. 2015;8:17634.

11. De Franco L, Marrelli D, Voglino C, et al. Prognostic Value of Perineural Invasion in Resected Gastric Cancer Patients According to Lauren Histotype. Pathology \& Oncology Research. 2018;24:393-400.

12. Yagi Y, Seshimo A, Kameoka S. Prognostic factors in stage IV gastric cancer: univariate and multivariate analyses. Gastric Cancer. 2000;3:71-80. 
13. Samadi F, Nasr ED, Sajadi A, et al. Survival rate of gastric and esophageal cancers in Ardabil province, North-West of Iran. 2007.

14. Tokunaga M, Ito S, Yoshikawa T, et al. Prognostic factors for survival in patients with pT1 N+ or T2-3 N0 gastric cancer in Japan. Br J Surg. 2017;104:885-90.

15. Zeraati H, Mahmoudi M, Mohammad K, Kazemnejad A, Mohagheghi M, Mir M. Postoperative survival in gastric cancer patients and its related factors. Journal of School of Public Health and Institute of Public Health Research. 2005;3:1-2.

16. Sachlova M, Majek O, Tucek S. Prognostic value of scores based on malnutrition or systemic inflammatory response in patients with metastatic or recurrent gastric cancer. Nutr Cancer. 2014;66:1362-70.

17. Buonadonna A, Lombardi D, De AP, Bidoli E, Frustaci S. Adenocarcinoma of the stomach: univariate and multivariate analyses of factors associated with survival. I supplementi di Tumori: official journal of Società italiana di cancerologia[et al]. 2003;2:S31-4.

18. Numaraları S, Yücel B, Akkaş EA, ve ark. Mide kanserli hastalarda adjuvan kemoradyoterapi: Tek merkez deneyimi.

19. Kanagavel D, Pokataev IA, Fedyanin MY, et al. A prognostic model in patients treated for metastatic gastric cancer with second-line chemotherapy. Ann Oncol. 2010;21:1779-85.

20. Green D, de Leon SP, Leon-Rodriguez E, Sosa-Sanchez R. Adenocarcinoma of the stomach: univariate and multivariate analysis of factors associated with survival. Am J Clin Oncol. 2002;25:84-89.
21. Wang W, Li Y-F, Sun X-W, et al. Prognosis of 980 patients with gastric cancer after surgical resection. Chin J Cancer. 2010;29:923-30.

22. Bozzetti F, Marubini E, Bonfanti G, Miceli R, Piano C, Gennari L. Subtotal versus total gastrectomy for gastric cancer: five-year survival rates in a multicenter randomized Italian trial. Italian Gastrointestinal Tumor Study Group. Ann Surg. 1999;230:170-78.

23. Mita $\mathrm{K}$, Ito $\mathrm{H}$, Katsube $\mathrm{T}$, et al. Prognostic Factors Affecting Survival After Multivisceral Resection in Patients with Clinical T4b Gastric Cancer. J Gastrointest Surg. 2017;21:1993-99.

24. Zare A, Mahmoodi M, Mohammad K, Zeraati H, Hosseini M, Holakouie Naieni K. Factors Affecting the Survival of Patients with Gastric Cancer Undergone Surgery at Iran Cancer Institute: Univariate and Multivariate Analyses. Iran J Public Health. 2014;43:800-08.

25. $\mathrm{Xu}$ J, Zhang $\mathrm{C}, \mathrm{He} \mathrm{Y}$, et al. Lymphatic endothelial cellsecreted CXCL1 stimulates lymphangiogenesis and metastasis of gastric cancer. Int J Cancer. 2012;130:78797.

26. Cao F, Hu YW, Li P, et al. Lymphangiogenic and angiogenic microvessel density in chinese patients with gastric carcinoma: correlation with clinicopathologic parameters and prognosis. Asian Pac J Cancer Prev. 2013; 14:4549-52. 